\title{
A novel role for CD46 in wound repair
}

\author{
John Cardone, Samia Al-Shouli and Claudia Kemper* \\ MRC Centre for Transplantation, King's College London, Guy's Hospital, London, UK
}

Edited by:

Uday Kishore, Brunel University, UK

\section{Reviewed by:}

Uday Kishore, Brunel University, UK Chenhui Zou, Brigham and Women's Hospital, USA

\section{*Correspondence}

Claudia Kemper, MRC Centre for Transplantation, King's College London, Guy's Hospital, 5th Floor, Tower Wing, Great Maze Pond, London SE1 9RT, UK.

e-mail: claudia.kemper@kcl.ac.uk
The intestinal epithelium not only provides a vital physical barrier between the host and environment but is also required for uptake of nutrients and the induction of tolerance against commensals. Deregulation of any of these functions leads to several disease states including chronic infection, inflammatory bowel disease, and cancer. Here, we describe a novel role for the complement regulator CD46 in the regulation of intestinal epithelial cell (IEC) barrier function. We found that CD46 directly interacts in IECs with the cytoplasmic kinase SPAK and with transmembrane E-cadherin, both proteins necessary for epithelial cell junction and barrier formation. Further, CD46 activation on Caco-2 cells induced rapid and significant decrease in transepithelial resistance with concomitant increase in paracelIular permeability. Importantly, though CD46 activation of IEC layers allowed for increased transgression of pathogenic $E$. coli, it also increased epithelial cell proliferation and accelerated wound repair. These data suggest a previously unappreciated role for CD46 in the maintenance of epithelial cell barrier integrity as well as barrier repair. However, this role for CD46 as "gate keeper" of the epithelium could also provide reason as to why so many pathogens bind to CD46 as such event would facilitate infection.

Keywords: CD46, complement, mucosal immunity, epithelial cells, wound healing

\section{INTRODUCTION}

The surface covered by the epithelium of the human intestinal mucosa is estimated to be $300 \mathrm{~m}^{2}$. It represents the widest surface of the body and defines the interface between the host and the external environment (Lotz et al., 2007). Intestinal epithelial cells (IECs) provide an innate barrier between the body and the gut lumen containing commensal bacteria and "non-self" food-derived antigens, while simultaneously allowing exchange of nutrients, electrolytes, and water (Menard et al., 2010). Thus, IECs are constantly exposed to harmless microorganisms and perform a major task by remaining tolerant and avoiding an inflammatory reaction to resident commensals while staying responsive toward invading pathogens (Mueller and Macpherson, 2006).

Equally fundamental though to the ability of tolerance induction is the integrity and polarity of IECs as well as its reconstitution after injury to avoid local or systemic bacteria dissemination (Sansonetti, 2004). The selective paracellular permeability across the epithelial monolayer is restricted and modulated by several types of intercellular junctions including tight junctions (TJ), adherence junction (AJ), and desmosome-like junctions (DS; Menard et al., 2010). TJs seal the paracellular space and help maintaining IECs structural and functional polarity (Furuse et al., 1998). These dynamic structures encircle epithelial cells at the apical end of lateral membranes while AJ and DS bridge lateral surfaces between cells. TJs are composed of members of the occludin and claudin proteins families and selectively open and close in response to incoming signals such as cytokines and growth or stress factors (Sansonetti, 2004). The E-cadherin/catenin network constitutes the major part of AJs and is vitally required for normal cell/cell interactions and epithelial cell layer function (Vermeulen et al., 1999; Van Aken et al., 2001; Kobielak and Fuchs, 2004; Yamada et al., 2005). E-cadherin can form homotypic dimers linking adjacent epithelial cells thereby functioning as intercellular anchor. $\alpha$ E-catenin binds to the intracellular portion of E-cadherin thereby connecting E-cadherin to the actin cytoskeleton and also transmitting EGF/Wnt-mediated signals regulating protein degradation as well as gene expression in epithelial cells (Yamada et al., 2005). Deregulation or dysfunction of proteins involved in TJ and/or AJ formation or function disrupt the normal epithelial barrier integrity leading to activation of intestinal immunity and exposure of internal tissues to commensal or pathogenic microorganisms (Sansonetti, 2004). This can cumulate in chronic inflammation and barrier dysfunction which is characteristic of inflammatory bowel diseases (IBDs) such as Crohn's disease and ulcerative colitis (Hugot et al., 2001; Ogura et al., 2001). In addition, mutations in E-cadherin, $\alpha$-E-catenin, or occludins as well the deregulation of their expression profiles are implicated in various steps of intestinal cancer development (Vermeulen et al., 1999; Kobielak and Fuchs, 2004).

CD46 is a ubiquitously expressed type I transmembrane glycoprotein and was initially discovered as a complement regulatory protein: $\mathrm{CD} 46$ binds the opsonins $\mathrm{C} 3 \mathrm{~b}$ and $\mathrm{C} 4 \mathrm{~b}$, acts as a cofactor in their factor I-mediated proteolytic degradation and thereby inhibits unwanted complement deposition on host tissue (Liszewski et al., 1991). Beside its role as a complement regulator, CD46 is also involved in fertilization processes (Riley et al., 2002) the regulation of Th1 cell responses (Astier et al., 2000; Kemper et al., 2003; Sanchez et al., 2004; Kemper and Atkinson, 2007; Cardone et al., 2010) and serves as a cell entry receptor for an increasing number of major human pathogens (Cattaneo, 2004; Cardone et al., 2010). CD46 is generally expressed in four isoforms that arise from a single alternatively spliced gene (Kemper et al., 2005). 
All isoforms contain at the N-terminus four complement control protein repeats (CCPs), followed by a differentially spliced highly O-glycosylated region, a transmembrane anchor and then one of two alternatively spliced intracellular tails, designated as CYT-1 and CYT-2 (Liszewski et al., 1991; Riley-Vargas et al., 2004). Both of these intracellular domains contain several conserved phosphorylation and signaling motifs and CD46 induces intracellular signaling events on several human cell types (Riley-Vargas et al., 2004).

A number of studies suggest that CD46 also plays a role in the polarization of human epithelium. In fact, the tail CYT-1 of CD46 binds to the protein DLG4 in kidney epithelial cells and this interaction is important for cell polarization (Ludford-Menting et al., 2002). Also, the interaction of CD46 with Neisseria meningitidis or N. gonorrhoeae (two of the CD46-binding pathogens) plays an important role in colonization of several human epithelial cells by this pathogen The CD46/Neisseria interaction leads to different epithelial cell modifications including: the transmission of intracellular signals by CD46, rearrangement of the cytoskeleton, calcium flux, and ultimately bacterial uptake by the epithelial cell (Kallstrom et al., 1998; Lee et al., 2002; Crimeen-Irwin et al., 2003; Gill and Atkinson, 2004). Similarly, CD46 is required for internalization of opsonized uropathogenic Escherichia coli by human kidney epithelial cells and a deficiency in CD46 leads to a decrease in microbe internalization (Li et al., 2006). Lastly, mice transgenic for human CD46 (rodents do not express CD46 on somatic tissue; Inoue et al., 2003) show an increased transgression of N. meningitides through the blood brain barrier compared to wild type animals and are more susceptible to lethal meningococcal disease (Johansson et al., 2005).

We have recently published on a novel interaction between CD46 and the Ste20/SPS1-related serine/threonine kinase (SPAK) in human $\mathrm{CD}^{+}{ }^{+} \mathrm{T}$ cells identified by a yeast-two-hybrid screen. We have shown that the CD46/SPAK interaction is required to switch IFN- $\gamma$-producing Th1 cells from this pro-inflammatory into an IL10-secreting (self)regulative state (Cardone et al., 2010). However, SPAK is better known for its function in osmotic stress regulation (Li et al., 2004; Smith et al., 2008) as well as regulation of intestinal barrier integrity (Yan et al., 2007, 2009). In fact mutations of SPAK in humans are connected with reduced epithelial cell/cell adhesion and onset of IBD (Yan et al., 2007). Further, we have now also identified E-cadherin and $\alpha$-E-catenin as potential binding partners for the intracellular domain(s) of CD46 within the same yeast-two-hybrid screen. These observations together prompted us to investigate whether CD46-mediated signaling events communicate with the E-cadherin/catenin network or SPAK in IECs and contribute to epithelial cell barrier integrity. Utilizing Caco2 in vitro trans-well and culture systems, we found that CD46 activation - surprisingly and counter-intuitively to the usually immunoprotective function of complement - reduced transepithelial resistance and increased paracellular permeability of IEC monolayers. However, though CD46 activation allowed thereby for an increased transgression of pathogenic bacteria across the cell layer, it also induced increased cell proliferation and accelerated wound healing. These data suggest that CD46 plays a previously unacknowledged role in the regulation of epithelial cell barrier integrity and repair - and may provide an additional reason (beside the observed negative regulation of Th1 cell immunity via CD46) as to why pathogens chose CD46 as cell receptor.

\section{MATERIALS AND METHODS CELLS AND BACTERIA}

The human intestinal cell line Caco-2 (clone HTB-37) was obtained from ECACC (European Collection of Cell Cultures, Health Protection Agency Culture Collection, Salisbury, UK) and cultured according to the standard protocol in Dulbecco's modified Eagle's medium (DMEM) supplemented with $10 \%$ heat-inactivated fetal calf serum, $1 \%$ non-essential amino acids, $100 \mathrm{U} / \mathrm{ml}$ penicillin, $100 \mu \mathrm{g} / \mathrm{ml}$ streptomycin, and $2 \mathrm{mM}$ L-Glutamine. Depending on the experimental set up, cells were cultured in gelatin-coated 48-well plates (Iwaki, Asahi Glass Co., Ltd., Japan), 24 trans-well systems (polycarbonate membrane, pore size $0.4 \mu \mathrm{m}$, membrane insert $\varnothing 12 \mathrm{~mm}$; Corning, USA) or in wells provided by the CytoSelect ${ }^{\mathrm{TM}}$ 24-Well Wound Healing Assay (Cell Biolabs Inc., USA) for 6-7 days minimum to a fully confluent monolayer. Epithelial cell layer integrity (i.e., formation of functional TJs and AJs) was monitored by (transepithelial resistance) TER measurement where applicable. The uropathogenic $E$. coli strain J96 is a serum-resistant, hemolysin-secreting strain that expresses type 1 and $\mathrm{P}$ fimbriae and was obtained from ATCC (clone 700336). J96 bacteria were grown in Luria-Bertani broth (Sigma Aldrich, Saint Louis, USA) and bacteria numbers assessed by photospectrometry at $600 \mathrm{~nm}$.

\section{ANTIBODIES AND REAGENTS}

The monoclonal antibody clones TRA-2-10 (against SCR 1 of CD46) and GB-24 (against SCRs 3 and 4) were a gift from John Atkinson, (Washington University of Saint Louis, MO, USA; Liszewski et al., 2000) and the monoclonal control antibody clone MOPC-21 was purchased from BD Biosciences (San Jose, CA, USA). TRA-2-10 and MOPC-21 were labeled with PE using the Invitrogen Zenon ${ }^{\circledR}$ Mouse R-phycoerythrin Mouse IgG Iabel- $_{1}$ ing Kit (Invitrogen, Carlsbad, CA, USA). The rabbit polyclonal anti-SPAK antibody was custom-generated by Invitrogen using a peptide spanning aa 403-419 of SPAK for immunization (Cardone et al., 2010) and antibodies raised against human E-cadherin (FITC) and $\alpha$-E-catenin as well as Annexin-APC were obtained from BD Biosciences. Horseradish peroxidase (HRP)-conjugated "secondary" antibodies for the detection of primary Abs in western blot analyses were from Amersham (Biosciences, Piscataway, NJ, USA). The Staurosporine, propidium iodide, and FITC-labeled dextran beads of $5 \mathrm{kDa}$ size were bought from Sigma Aldrich.

\section{CO-IMMUNOPRECIPITATION}

Caco-2 cells were cultured for 7 days in gelatin-coated 24-well plates. A mAb to CD46 (TRA-2-10) or an isotype control mAb was added at $10 \mu \mathrm{g} / \mathrm{ml}$ for $3 \mathrm{~h}$. Cells were then lysed in lysis buffer [1\% v/v maltoside, $50 \mathrm{mM}$ Tris- $\mathrm{HCl}(\mathrm{pH} 8.0), 150 \mathrm{mM} \mathrm{NaCl}$, $1 \mathrm{mM}$ EDTA, $1.5 \mathrm{mM} \mathrm{MgCl}, 10 \%$ glycerol], and protease and phosphatase inhibitors (Sigma Aldrich). Lysates were incubated with a mAb GB-24 (anti-CD46) or an isotype-matched control $\mathrm{mAb}$ covalently coupled to Sepharose (Amersham) overnight at $4^{\circ} \mathrm{C}$. After washing, bound proteins were eluted, quantitated and analyzed by Western blotting under reducing conditions. 


\section{MEASUREMENT OF TRANSEPITHELIAL RESISTANCE AND PARACELLULAR PERMEABILITY}

To assess the effect of CD46 activation on epithelial cell barrier integrity of Caco- 2 cells, TER, and paracellular permeability were measured in cell cultures before and after CD46 activation. TER: Caco-2 cells were cultured in 24-well trans-well plates for up to 10 days and TER was measured daily using the EVOM2 (epithelial voltohmmeter, World Precision Instruments Inc., Sarasota, FL, USA) and STX2 “chopstick" electrodes as per manufacturer's protocol. When TER reached a minimum of $1000 \Omega / \mathrm{cm}^{2}$, either monoclonal antibodies (mAbs) to CD46, an isotype control mAb $(10 \mu \mathrm{g} / \mathrm{ml})$, or EtOH (final concentration of $15 \%)$ was added to the upper chamber and TER measured at different time points post activation. Paracellular permeability: Caco-2 cells were cultured in 24-trans-wells until they reached a minimum TER of $1000 \Omega / \mathrm{cm}^{2}$. FITC-labeled dextran beads of a $5-\mathrm{kDA}$ size $(1 \mathrm{mg} / \mathrm{ml})$ or $10^{7} \mathrm{~J} 96$ bacteria/ml that had been fluorochrome-labeled utilizing the $\mathrm{PKH}$ and CellVue ${ }^{\circledR}$ Claret Fluorescent Cell Linker Dyes (Sigma Aldrich, Saint Louis, USA) were added to the upper chamber with or without the addition of mAb to CD46, an isotype control $\mathrm{mAb}$ or $\mathrm{EtOH}$ ( $15 \%$ final concentration). At different time points, aliquots of the cell medium were collected from the upper and lower chamber. Transgression rate of labeled dextran beads was determined by measuring accumulated fluorescence in these samples with a Fluorescence Optimeter (FLUOstar Omega, BMG Labtech, Aylesbury, $\mathrm{UK})$ at $530 \mathrm{~nm}$ while transgression of bacteria was monitored by flow cytometric analysis of samples using a FACSCalibur ${ }^{\mathrm{TM}}$ (Becton Dickinson, Oxford, UK) and the VenturiOne program (Applied Cytometry, Sheffield, UK) for analysis.

\section{CELL PROLIFERATION MEASUREMENT}

Caco-2 cells were seeded into 24 -well plates at varying starting dilutions and cultured over night. mAbs to CD46, an isotype control $\mathrm{mAb}(10 \mu \mathrm{g} / \mathrm{ml})$ or staurosporine $(200 \mu \mathrm{M})$ were then added and cell proliferation rates were measured utilizing the CellTiter 96 ${ }^{\circledR}$ AQueous One Solution Cell Proliferation Assay from Promega (Madison, WI, USA) at different time points according to the manufacturer's protocol.

\section{WOUND HEALING ASSAY}

Caco-2 cells were cultured in 24-wells provided by the CytoSelect $^{\mathrm{TM}} 24$-Well Wound Healing Assay Kit. At day 7 of culture, the linear spacer inserted in the well was removed, which created a regular and defined "wound" within the cell monolayer. Wells were either left untreated or treated with $10 \mu \mathrm{g} / \mathrm{ml} \mathrm{mAb}$ to CD46 or an isotype control $\mathrm{mAb}$ (conditions were performed in triplicate) and further cultured. Closure of wound areas was monitored by time-laps microscopy [Canon EOS 50D (Canon UK Ltd., Surrey) ] and digital pictures were analyzed using MetaMorph software (Molecular Devices, Downingtown, PA, USA).

\section{STATISTICAL ANALYSIS}

Variables are represented as mean $\pm \mathrm{SD}$. One-factor analysis of the paired Student's $t$-test [Excel software (Microsoft, Redmond, WA, USA)] was used for data analyses and statistical significance was set at $p<0.005$.

\section{RESULTS}

CD46 INTERACTS WITH OR MODULATES EXPRESSION OF PROTEINS REQUIRED FOR MAINTENANCE OF EPITHELIAL CELL LAYER INTEGRITY

Although both of CD46's intracellular domains CYT-1 and CYT2 can transmit intracellular signals in several cell types (Wang et al., 2000; Riley-Vargas et al., 2004; Astier and Hafler, 2007), the exact pathways translating into CD46's biological functions remain mostly unknown. Using a yeast-two-hybrid screen with a Jurkat T cell library as a "bait" source, we have previously observed that the Ste20/SPS1-related kinase (SPAK) interacts with CD46 CYT- 1 and CYT-2 in primary human CD $4^{+} \mathrm{T}$ cells (Cardone et al., 2010). SPAK is a broadly expressed serine/threonine kinase with key roles in MAPK activation (Johnston et al., 2000; Delpire and Gagnon, 2008). Though we observed that the SPAK/CD46 interaction is required for CD46-driven IL-10 production in $\mathrm{T}$ cells (in line with a role for SPAK in $\mathrm{T}$ cell activation; $\mathrm{Li}$ et al., 2004), SPAK was initially discovered as a stress-induced key regulator of ion co-transporters (Delpire and Gagnon, 2008), systemic fluid homeostasis (San-Cristobal et al., 2009) and regulator of IEC layer integrity (Yan et al., 2007). In addition to SPAK, we also identified $\alpha$-E-catenin and the intracellular portion of E-cadherin as CD46-interacting proteins in the same yeast-two-hybrid screen. $\alpha$-E-catenin and E-cadherin are key constituents of the E-cadherin/catenin network forming the AJs that are vitally required for normal cell/cell interactions and epithelial cell layer maintenance (Vermeulen et al., 1999; Van Aken et al., 2001; Kobielak and Fuchs, 2004; Yamada et al., 2005). The interaction of CD46 with these proteins suggested to us that CD46 may function in the regulation of IEC barrier regulation and we first assessed if CD46 indeed binds to SPAK, $\alpha$-E-catenin, or E-cadherin in the human epithelial colorectal adenocarcinoma cell line, Caco2. These cells express CD46 on the apical as well as basolateral surfaces (Sinn et al., 2002; and data not shown). Immunoprecipitation confirmed that SPAK constitutively bound to CD46 in Caco-2 cells, while the E-cadherin/CD46 interaction was only observed when the cells were activated with mAbs to CD46 (Figures 1A,B). In contrast, we have not been able to co-immunoprecipitate CD46 and $\alpha$-E-catenin in Caco- 2 cells under any activation conditions tested (Figure 1B; of note, however, we can co-immunoprecipitate CD46 and $\alpha$-E-catenin in human CD4 ${ }^{+}$T cells, not shown). We further observed that CD46 cross-linking increases E-cadherin expression on Caco-2 cells (Figure 1C) but does not impact on SPAK or $\alpha$-E-catenin expression levels (data not shown). Successful CD46 activation throughout these experiments was monitored by CD46 downregulation (Figure 1D) - which is an acknowledged consequence of CD46 stimulation observed on any cell type analyzed so far (Riley-Vargas et al., 2004).

\section{CD46-MEDIATED SIGNALS REGULATE INTESTINAL EPITHELIAL BARRIER FUNCTION}

In the previous set of data, we established a novel connection between CD46 and proteins involved in the maintenance and regulation of the intestinal epithelium (Vermeulen et al., 1999; Van Aken et al., 2001; Kobielak and Fuchs, 2004; Yamada et al., 2005; Yan et al., 2007, 2009). We next assessed potential functional implications of this new link and determined whether CD46-induced signals can modulate epithelial barrier integrity in Caco-2 cells 
A

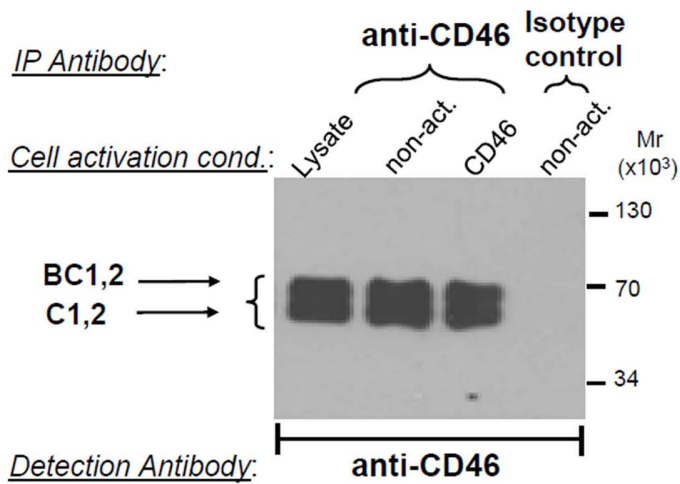

C
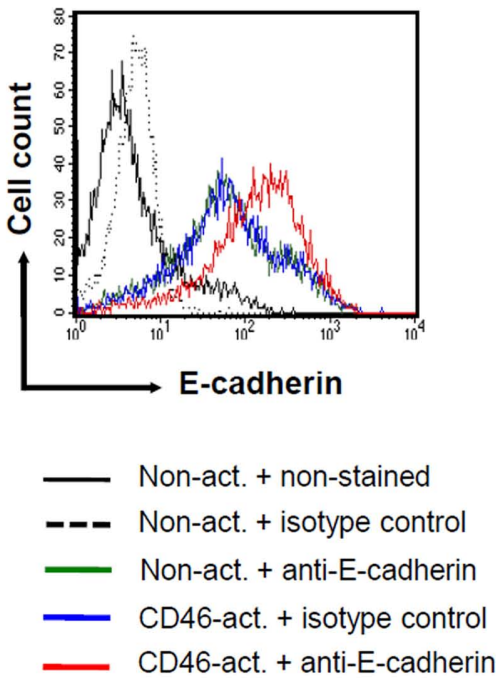

B
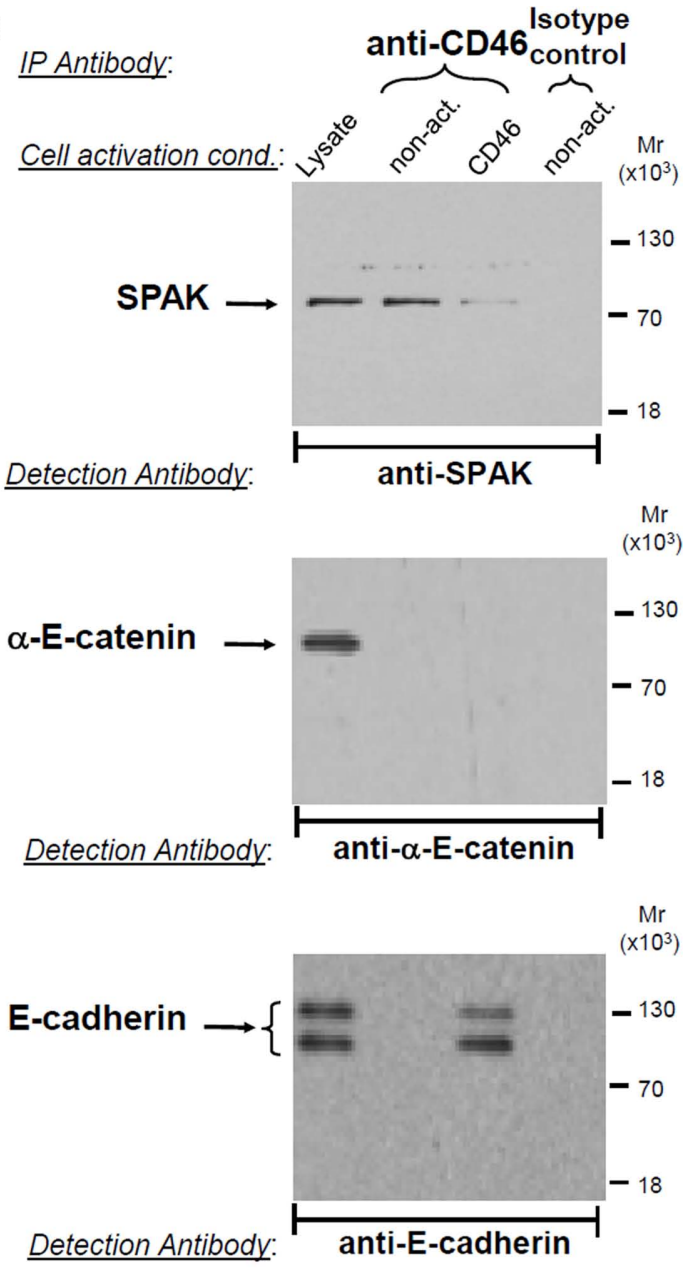

D

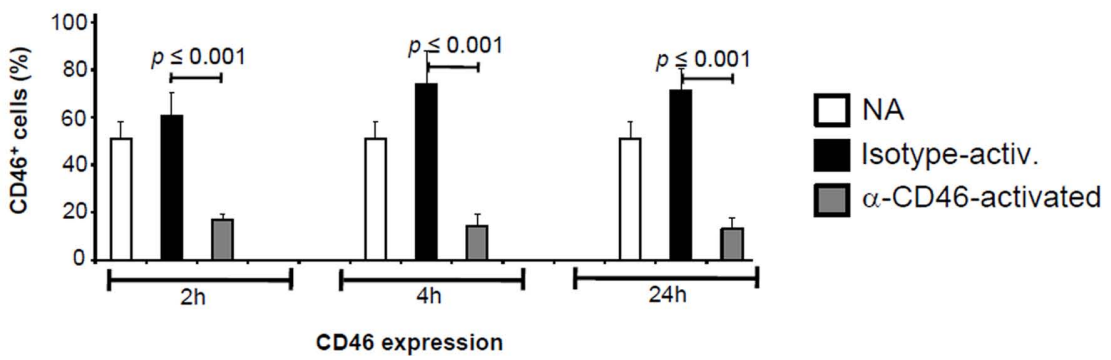

FIGURE 1 | CD46 interacts with and/or modulates expression of proteins required for intestinal epithelial cell layer integrity. (A,B) CD46 associates with SPAK and E-cadherin in human colon epithelial cells. Caco-2 cells were activated for $3 \mathrm{~h}$ by receptor cross-linking using the antibodies indicated, and cell lysates used for immunoprecipitation with a CD46-specific or isotype control mAb. Immunoblotting with an anti-CD46 mAb assessed successful precipitation while anti-SPAK, anti- $\alpha$-E-catenin, and anti-E-cadherin antibodies revealed an association between CD46 and SPAK and CD46 and E-cadherin. Untreated lysates from non-activated cells were loaded as control ("lysate"). Data are representative of three similarly performed experiments. (C) CD46 activation increases E-cadherin expression in Caco-2 cells. Caco-2 cells were either left non-activated or activated as described under (A) (but for $12 \mathrm{~h}$ ) and E-cadherin expression levels determined via FACS analysis. CD46 activation did not modulate $\alpha$-E-catenin or SPAK expression levels (data not shown). FACS plot shown is representative of three separately but similarly performed experiments. (D) CD46 activation of Caco-2 cells induces rapid CD46 downregulation. Caco-2 cells were activated as indicated and CD46 expression levels measured at 2, 4, and $24 \mathrm{~h}$ post activation. Data represent mean $\pm \mathrm{SD}(n=3)$. NA, non-activated. cultured in a trans-well system. The formation of intercellular TJs and $\mathrm{AJs}$ is a rate-limiting barrier, inhibiting paracellular flow of ions and larger solutes and resulting in measurable differences in the ion concentration between the upper and lower chamber of 
the trans-well. These ion differences are measured and expressed as TER. Caco- 2 cells were cultured for up to 10 days and functional barrier formation through TJ and AJ assembly monitored via increasing TER (Figure 2A). mAbs to CD46 were added to Caco-2 cultures with a TER $\geq 1000 \Omega / \mathrm{cm}^{2}$. Within 30 min post activation TER decreased by $70 \%$ of the initial value while an isotype control $\mathrm{mAb}$ showed only marginal TER decrease (Figure 2B). Ethanol (EtOH), a cell toxin was added in concentrations above 5-10\%,
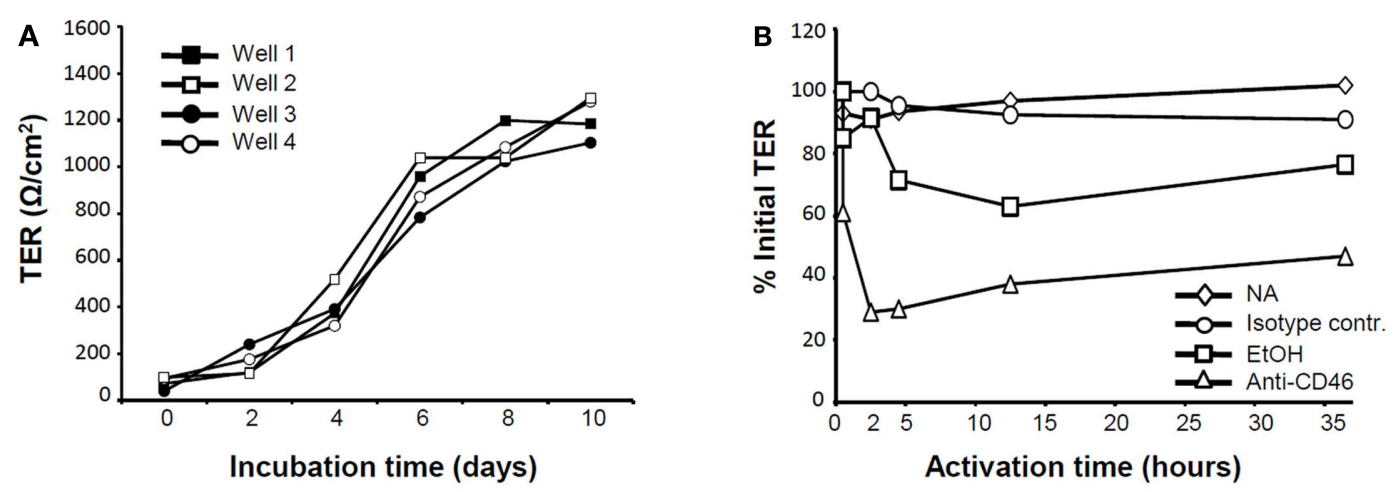

C

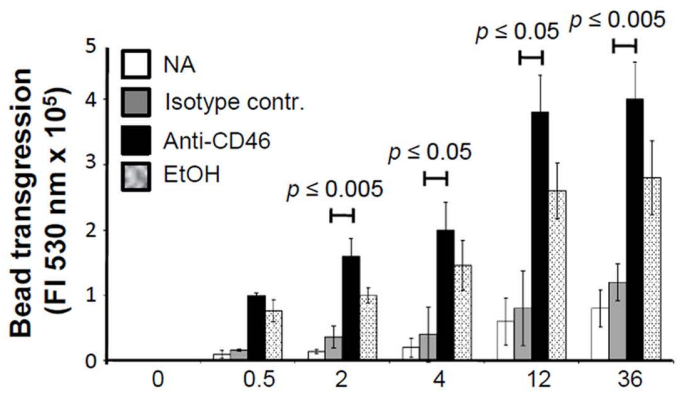

Activation time (hours)

D

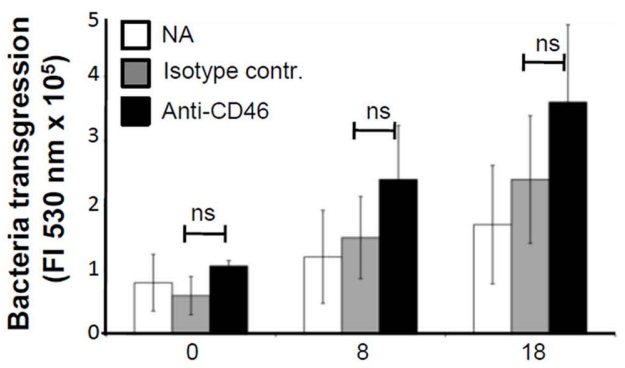

Activation time (hours)

E

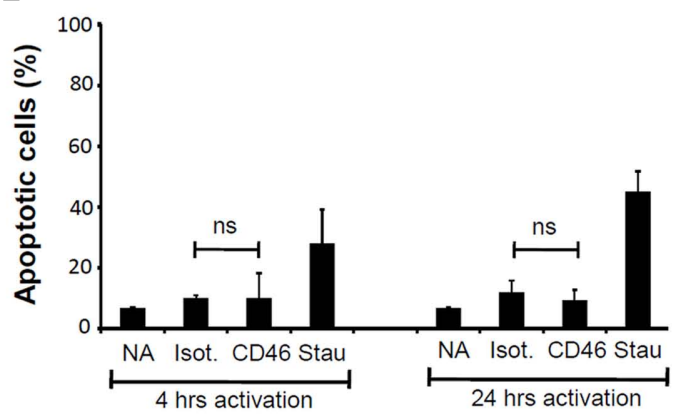

Activation condition

FIGURE 2 | CD46 regulates epithelial cell barrier integrity in Caco-2 cell monolayers. (A) Caco-2 cell monolayers form functional TJs and AJs. Caco-2 cells were seeded at $5 \times 10^{4}$ cells/well in the upper well of a trans-well system. TER, a measure of functional TJ and AJ formation) was assessed every 2 days for a period of 10 days. Shown is the TER measured in four wells over 10 days. Data are representative of three similarly performed experiments. (B) CD46 activation decreases TER. Caco-2 cells were cultured in trans-wells until a minimum of $1000 \Omega / \mathrm{cm}^{2}$ was reached. Either anti-CD46 $\mathrm{mAb}$, an isotype control $\mathrm{mAb}$ or $15 \%$ final concentration $\mathrm{EtOH}$ were added to the upper well and TER measured at the indicated time points. Activation conditions were performed in triplicate (data shown are mean value) and shown is the result of one of three similarly performed experiments. (C) CD46 activation increases paracellular permeability. Caco-2 cells were grown and activated as described under (A) but with the addition of FITC-labeled dextran beads ( $5 \mathrm{kDa}$ size) into each upper chamber. At indicated time points, sample aliquots were taken from the lower trans-well chambers and the amount of transgressed beads measured. Shown is one representative of three similarly performed experiments. (D) CD46 activation increases transgression of uropathogenic bacteria. Experiments were performed as under (C) but with the addition of $\mathrm{J} 96$ bacteria instead of dextran beads into the upper chamber. Data shown are mean \pm SD of two similarly performed experiments. (E) CD46 activation does not induce apoptosis or cell death. Caco-2 cells were cultured in 24-wells for 6 days. Wells were either left non-activated or treated with mAb to CD46, an isotype control mAb or staurosporine, an apoptosis-inducing agent. Apoptosis was analyzed by combined Annexin and propidium iodide staining at 4 and $24 \mathrm{~h}$ post activation. Data shown are the mean $\pm S D$ and representative of four experiments. NA, non-activated; Stau, staurosporine; ns, statistically not significant. 
to the cultures as a positive control and reduced TER to about $60 \%$ albeit with slower kinetics compared to CD46 activation (Figure 1B). Reduction of TER was maintained in the presence of CD46 activation for up to $36 \mathrm{~h}$ (Figure 1B). However, when CD46-activating mAbs were removed after activation, TER was fully restored within 2-3 days (data not shown), indicating that CD46-mediated TER decrease is a reversible process.

The biological function of TER regulation includes epithelial cell growth control (see below) and the controlled transport or transgression of solutes and particles between the paracellular space of epithelial cells via the "opening" of TJs and AJs. Evidence underpinning that CD46 activation of Caco- 2 cells indeed regulates paracellular permeability was provided by our observation that the addition of CD46 cross-linking mAbs to cell cultures increased the transgression of FITC-labeled $5 \mathrm{kDa}$ dextran beads from the upper to the lower trans-well chamber significantly (Figure 2C). Importantly, the kinetics of CD46-induced bead transgression are fully in line with those observed for CD46mediated TER changes (Figure 2B). To assess CD46's function in epithelial cell barrier function toward a more physiological "agent," we next analyzed the transgression of the uropathogenic E. coli strain 596 in the presence of CD46 activation (Figure 2D). Similarly to the experiments using beads, E. coli bacteria accumulated faster and in higher numbers in the lower trans-well chamber when CD46 activation took place. The high statistical deviation observed when bacteria were used in the transgression experiments is likely due to the more complex interaction of the microbes with the epithelial cells (i.e., concurrent activation of toll-like receptors etc.) compared to the usage of beads.

Importantly, the observed CD46-mediated increase in TER and paracellular permeability in Caco-2 cell cultures are not due to increased apoptosis or cell stress as neither the addition of mAbs to CD46 nor the isotype control mAb increased Annexin V binding (or propidium iodine staining, data not shown; Figure 2E). Thus, these data indicate that CD46 activation modulates TJ and $\mathrm{AD}$ expression or function and by this decreases barrier function of IECs.

\section{CD46 ACTIVATION PROMOTES CELL GROWTH AND ACCELERATES WOUND HEALING IN INTESTINAL EPITHELIAL CELLS}

Proliferation of epithelial cells is controlled by contact inhibition. In this process, the formation and constellation of TJ and AJ eventually induces growth stop while a decrease in TJ and/or AJ or impairment of their integrity initiates cell proliferation (Zeng and Hong, 2008). We therefore assessed if CD46-mediated modulation of TJ and AJ formation impacts on Caco-2 cell proliferation. Caco2 cells were activated with either CD46 mAbs, an isotype-specific control mAb or treated with staurosporine for 24 or $48 \mathrm{~h}$ and then assessed for cell proliferation (Figure 3A). Whilst staurosporine treatment induced, as expected, cell death, CD46-activated cells showed a significant increase in proliferation compared to the control mAb-treated cultures.

We confirmed the effect of CD46-mediated signals on epithelial cell growth using a wound healing assay. Caco- 2 cells were cultured on 24-wells with a removable insert that created a defined "wound-like" area upon removal (Figure 3B, photographs). mAbs to CD46 or an isotype control $\mathrm{Ab}$ was added and cell growth monitored via time-lapse microscopy over $18 \mathrm{~h}$. In agreement with the data obtained in the proliferation assay (Figure 3A), we observed that CD46 engagement accelerated would closure significantly compared to the addition of control mAb (Figure 3B, lower graph).

In summary, we have shown here that CD46 interacts with SPAK and E-cadherin, proteins important for normal epithelial barrier function in IECs, and that CD46 activation decreases TER
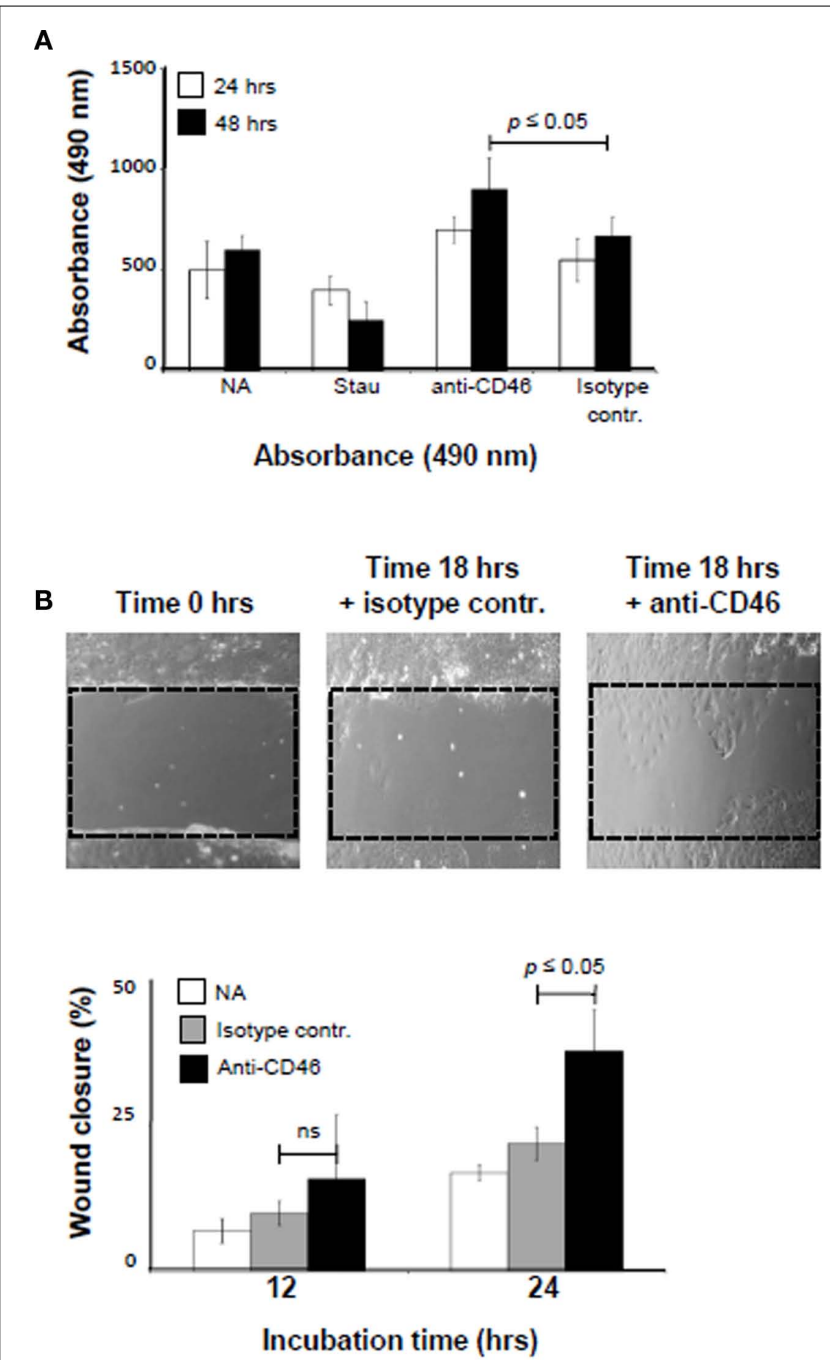

FIGURE 3 | CD46 activation accelerates wound healing. (A) CD46 activation increases cell proliferation. Caco-2 cells were seeded into 24 -wells at $1.5 \times 10^{4}$ cells/well and allowed to adhere over night. Wells were then left untreated or treated with $10 \mu \mathrm{g} / \mathrm{ml} \mathrm{mAb}$ to CD46, an isotype control mAb or staurosporine $(200 \mu \mathrm{M})$ and cell proliferation measured 24 and $48 \mathrm{~h}$ post treatment. Data shown are the mean $\pm \mathrm{SD}$ and representative of four experiments. (B) CD46 activation leads to accelerated wound closure. Caco-2 cells were cultured on 24-wells with a removable insert. After 6 days, the insert was removed and revealed a defined "wound-like" area (upper panels). mAbs to CD46 or an isotype control Ab was added and cell growth monitored via time-lapse microscopy. Lower panel shows the statistical analysis using MetMorph of the data obtained visually. Data shown are the mean \pm SD and representative of three experiments. ns, statistically not significant. 
and increases paracellular permeability and by this promotes cell growth and would healing in in vitro cultured Caco- 2 cells.

\section{DISCUSSION}

The complement system has been viewed traditionally as a sentinel system circulating in the blood and lymph with the rather simple task to directly kill bacteria or opsonize and tag them for uptake by phagocytes. From the early 1970s on, this view changed as it became apparent that complement activation participates in many processes of the adaptive immune arms as it is also required for the optimal induction of $\mathrm{B}$ and $\mathrm{T}$ cells responses as well as generation of lymphocyte memory pool (Ricklin et al., 2010; Cope et al., 2011). A flurry of recent studies now suggest an even broader functional repertoire of this ancient system as it seems that complement-mediated signaling events are equally necessary for the timely shut down of Th1 responses in humans, and by this for tolerance induction and immune homeostasis (Cardone et al., 2011).

Our finding that the complement protein CD46 regulates IECs barrier function would be fully in line with an expected guarding role of the complement system at such vital host/environment interface. In our experimental system, we have activated CD46 by mAbs. Natural non-pathogenic ligands for CD46 include the opsonins $\mathrm{C} 3 \mathrm{~b}$ and $\mathrm{C} 4 \mathrm{~b}$. The intestinal lumen contains high amounts of $\mathrm{C} 3$ and $\mathrm{C} 3 \mathrm{~b}$ and several types of epithelial cells secrete $\mathrm{C} 3$ (which is then converted to $\mathrm{C} 3 \mathrm{~b}$ ) upon activation by cytokines, tissue damage, or other stress signals (Moon et al., 1997). Thus, CD46 activation at this location can easily be envisioned in an in vivo setting. However, the observation that the addition of mAbs to CD46 decreased epithelial barrier was unexpected - specifically in the presence of pathogenic bacteria as one would content that "sensing" of danger by a complement component would rather increase barrier function to protect the host from infection. Our data are in good agreement with the observation that mice transgenic for human CD46 show increased transgression of pathogenic Neisseria through the blood brain barrier and subsequent high infection and mortality rate (Johansson et al., 2005). In fact, mice do not express CD46 on somatic cells (Inoue et al., 2003) and are usually not susceptible to pathogens targeting CD46 as cell entry receptor (Kemper et al., 2005).

The finding though that CD46 activation also increased cell proliferation and wound healing suggests that CD46's normal functional role on IECs may rather be homeostatic via the induction of barrier repair after pathogen breach or other injury (and that some pathogens plainly take advantage of this "housekeeping" function). The induction of epithelial cell proliferation and repair mechanism are induced via changes in TJ and AJ formation and signaling events triggered by those changes. Although the underlying mechanism is undefined, a vital role for complement activation in the repair after liver injury has previously been proposed as mice deficient for C3 and/or C5 fail to initiate hepatocyte proliferation and tissue repair in a liver injury model $(\mathrm{He}$ et al., 2009). Accordingly, patients with liver cirrhosis and impairment of tissue repair present with very low levels of circulating C3 and C4 (Nakamura et al., 1995). Interestingly, when we performed similar experiments using a tubular kidney epithelial cell line, we did not observe CD46-mediated changes in TER or proliferation, despite successful CD46 activation assessed by CD46 downregulation (data not shown). This may indicate that CD46's regulates epithelial barrier function at specific locations.

A better understanding of the exact mechanism(s) by which CD46 regulates $\mathrm{TJ}$ and/or $\mathrm{AJ}$ formation or activation will now require an assessment of the CD46-mediated signaling events post activation in these cells. There are several possibilities as to how CD46 could participate in barrier homeostasis. CD46-mediated signals could impact (possibly via SPAK and/or $\alpha$-E-catenin) on the expression level of TJ and AJ proteins (Figure 4A). We have indeed observed an increase in E-cadherin expression upon CD46 activation and any changes in E-cadherin expression are generally connected with AJ functional changes (Ayollo et al., 2009). Interestingly, this has also been observed for changes in $\alpha$-E-catenin and SPAK levels or functions (Kobielak and Fuchs, 2004; Yan et al., 2009). Studies on CD46-mediated impact in the expression of TJ proteins such as occludins and claudins have so far not been performed but will likely unravel also a cross-connection or-regulation axis as both TJs and AJs need to

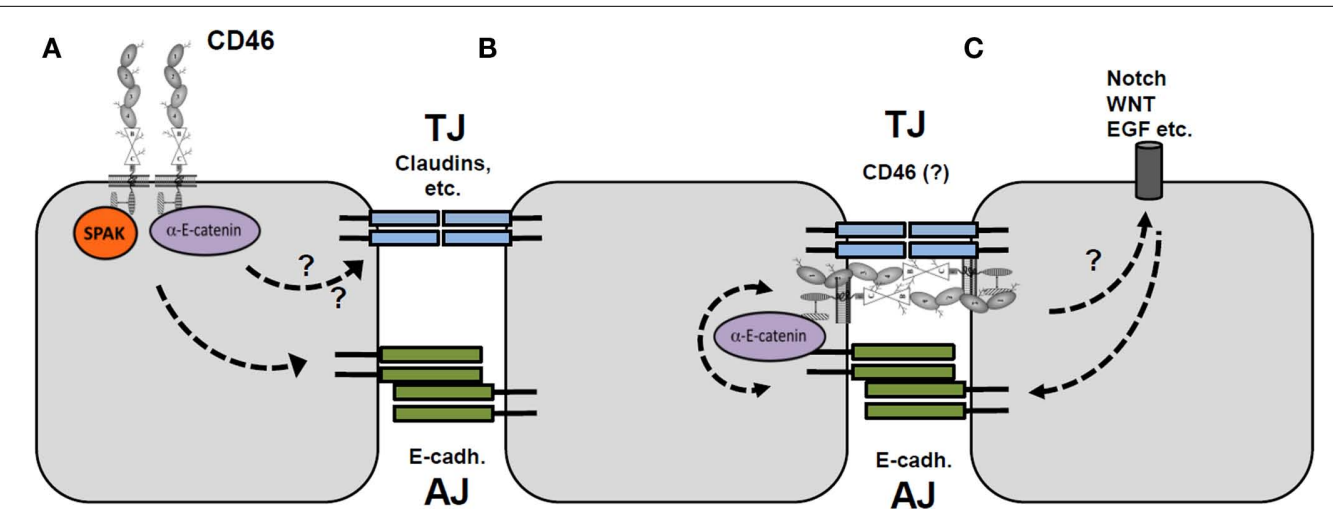

FIGURE 4 | Possible mechanisms of CD46-mediated epithelial cell barrier regulation. (A) Activation of CD46 expressed on the apical (or basal) surface of epithelial cells leads to signaling via SPAK and/or $\alpha$-E-catenin that regulates E-cadherin (AJ formation) and possibly TJ formation. (B) CD46 is part of TJs and its activation thereby directly impacts TJ formation and AJ function via the CD46/E-cadherin interaction. (C) CD46-mediated signals may regulate the Notch/Wnt pathways, which in turn impact on epithelial cell layer integrity. 
undergo modifications for TER changes. We did attempt to knock down protein expression of either CD46, SPAK, $\alpha$-E-catenin or E-cadherin via siRNA technique to assess which of those components act downstream of CD46 in intercellular junction and TER regulation (data not shown). However, and as it has been published, we found that knockdown of either SPAK, E-cadherin, or $\alpha$-E-catenin impaired proper Caco-2 cell monolayer formation and TER establishment (Yan et al., 2009). Interestingly, this was also the case after CD46 knock down (data not shown). Thus, these data clearly underscore the importance of these proteins in intestinal barrier function but also make it difficult to assess their functional interrelationship. However, the observation that CD46 knock down prevented TER establishment could suggest that CD46 may actually be an integral part of intercellular junctions themselves (Figure 4B). Indeed, this has been proposed previously in a study by Strauss et al. (2009) in which the authors showed that CD46 is located within the TJs of ovarian cancer cell lines and that adenovirus targeted CD46 during epithelialto-mesenchymal transition. Additionally, members of the DLG protein family have been implicated in TJ formation (Ivanov et al., 2010) and one of them, DLG4 has been shown to bind CD46 in kidney epithelial cells (Ludford-Menting et al., 2002).

As an interesting third option (and these models may not be mutually exclusive), we suggest a potential crosstalk between CD46 and the Notch and/or Wnt system in IECs (Figure 4C). This idea is based on our recent observation that CD46 regulates the expression of Notch 1 and 2 as well as their ligands jagged-1 and delta-1 in human CD4 ${ }^{+} \mathrm{T}$ cells (Le Friec et al., 2010; Cope et al., 2011). The Notch system is vitally important for homeostasis of IECs and transmits intracellular signals via the $\alpha$ - and $\beta$-catenin pathways (Peignon et al., 2011). Given these commonalities, it is feasible to suggest also a functional relationship between complement/CD46 and the Notch system in the gut epithelium.

\section{REFERENCES}

Astier, A., Trescol-Biemont, M. C., Azocar, O., Lamouille, B., and Rabourdin-Combe, C. (2000). Cutting edge: CD46, a new costimulatory molecule for $\mathrm{T}$ cells, that induces p120CBL and LAT phosphorylation. J. Immunol. 164, 6091-6095.

Astier, A. L., and Hafler, D. A. (2007). Abnormal $\operatorname{Tr} 1$ differentiation in multiple sclerosis. J. Neuroimmunol. 191, 70-78.

Ayollo, D. V., Zhitnyak, I. Y., Vasiliev, J. M., and Gloushankova, N. A. (2009). Rearrangements of the actin cytoskeleton, and E-cadherin-based adherens junctions caused by neoplasic transformation change cellcell interactions. PLoS ONE 4, e8027. doi: 10.1371/journal.pone.0008027

Cardone, J., Le Friec, G., Vantourout, P., Roberts, A., Fuchs, A., Jackson, I., Suddason, T., Lord, G., Atkinson, J. P., Cope, A., Hayday, A., and Kemper, C. (2010). Complement regulator CD46 temporally

A role for CD46 in the regulation of barrier function and growth could have major implications for several disease states. For example, disturbance in CD46-mediated TJ and AJ function (via mutations in CD46 leading to suboptimal or excessive signaling) could induce "leakage" of the gut flora from the lumen into the surrounding tissue and may cumulate into chronic inflammation such as observed in IBD (Hugot et al., 2001). This "phenotype" may be further potentiated by an impairment of CD46-mediated tissue/barrier repair. On the other hand, increased or uncontrolled induction of CD46-mediated cell proliferation may induce malignant transformation of epithelial cells and adenocarcinoma formation. Indeed, a mutation in CD46 that retains protein expression on the cell membrane as well as CD46's complement regulatory and ligand binding function but induces a nonsense mutation in the intracellular domains has been identified in a colon cancer patient (Sjoblom et al., 2006). In addition, DLG4 functions in drosophila as a tumor suppressor, and the CD46/DLG4 interaction may possibly serve in a similar pathway (Ludford-Menting et al., 2002).

Thus, delineating CD46's function in healthy epithelium homeostasis may provide an opening to further understand the impact of innate immune signals or their deregulation in chronic inflammation and/or malignant transformation.

\section{ACKNOWLEDGMENTS}

The work in this study was supported by the Kidney Patient Association (KPA), the Medical Research Council Center for Transplantation, Guy's Hospital, King's College and the Department of Health, National Institute for Health Research comprehensive Biomedical Research Centre award to Guy's and St. Thomas' NHS Foundation Trust in partnership with King's College London and King's College Hospital NHS Foundation Trust.

Delpire, E., and Gagnon, K. B. (2008). SPAK and OSR1: STE20 kinases involved in the regulation of ion homoeostasis and volume control in mammalian cells. Biochem. J. 409, 321-331.

Furuse, M., Sasaki, H., Fujimoto, K., and Tsukita, S. (1998). A single gene product, claudin-1 or -2 , reconstitutes tight junction strands and recruits occludin in fibroblasts. J. Cell Biol. 143, 391-401.

Gill, D. B., and Atkinson, J. P. (2004). CD46 in Neisseria pathogenesis. Trends. Mol. Med. 10, 459-465.

He, S., Atkinson, C., Qiao, F., Cianflone, K., Chen, X., and Tomlinson, S. (2009). A complementdependent balance between hepatic ischemia/reperfusion injury and liver regeneration in mice. J. Clin. Invest. 119, 2304-2316.

Hugot, J. P., Chamaillard, M., Zouali, H., Lesage, S., Cezard, J. P., Belaiche, J., Almer, S., Tysk, C., O’Morain, C. A., Gassull, M., Binder, V., Finkel, Y.,
Cortot, A., Modigliani, R., LaurentPuig, P., Gower-Rousseau, C., Macry, J., Colombel, J. F., Sahbatou, M., and Thomas, G. (2001). Association of NOD2 leucine-rich repeat variants with susceptibility to Crohn's disease. Nature 411, 599-603.

Inoue, N., Ikawa, M., Nakanishi, T., Matsumoto, M., Nomura, M., Seya, T., and Okabe, M. (2003). Disruption of mouse CD46 causes an accelerated spontaneous acrosome reaction in sperm. Mol. Cell. Biol. 23, 2614-2622.

Ivanov, A. I., Young, C., Den Beste, K. Capaldo, C. T., Humbert, P. O., Brennwald, P., Parkos, C. A., and Nusrat, A. (2010). Tumor suppressor scribble regulates assembly of tight junctions in the intestinal epithelium. Am. J. Pathol. 176, 134-145.

Johansson, L., Rytkonen, A., Wan, H., Bergman, P., Plant, L., Agerberth, B., Hokfelt, T., and Jonsson, A. B. (2005). Human-like immune responses in CD46 transgenic mice. J. Immunol. 175, 433-440. 
Johnston, A. M., Naselli, G., Gonez, L. J., Martin, R. M., Harrison, L. C., and DeAizpurua, H. J. (2000). SPAK, a STE20/SPS1-related kinase that activates the p38 pathway. Oncogene 19, 4290-4297.

Kallstrom, H., Islam, M. S., Berggren, P. O., and Jonsson, A. B. (1998). Cell signaling by the type IV pili of pathogenic Neisseria. J. Biol. Chem. 273, 21777-21782.

Kemper, C., and Atkinson, J. P. (2007). T-cell regulation: with complements from innate immunity. Nat. Rev. Immunol. 7, 9-18.

Kemper, C., Chan, A. C., Green, J. M., Brett, K. A., Murphy, K. M., and Atkinson, J. P. (2003). Activation of human CD4+ cells with CD3 and CD46 induces a T-regulatory cell 1 phenotype. Nature 421, 388-392.

Kemper, C., Verbsky, J. W., Price, J. D., and Atkinson, J. P. (2005). Tcell stimulation and regulation: with complements from CD46. Immunol. Res. 32, 31-43.

Kobielak, A., and Fuchs, E. (2004). Alpha-catenin: at the junction of intercellular adhesion and actin dynamics. Nat. Rev. Mol. Cell Biol. 5, 614-625.

Le Friec, G., Bugeon, L., Dallman, M., and Kemper, C. (2010). CD46: just a notch up your complement regulator. Mol. Immunol. 47, 2229.

Lee, S. W., Bonnah, R. A., Higashi, D. L., Atkinson, J. P., Milgram, S. L., and So, M. (2002). CD46 is phosphorylated at tyrosine 354 upon infection of epithelial cells by Neisseria gonorrhoeae. J. Cell Biol. 156, 951-957.

Li, K., Feito, M. J., Sacks, S. H., and Sheerin, N. S. (2006). CD46 (membrane cofactor protein) acts as a human epithelial cell receptor for internalization of opsonized uropathogenic Escherichia coli. J. Immunol. 177, 2543-2551.

Li, Y., Hu, J., Vita, R., Sun, B., Tabata, H., and Altman, A. (2004). SPAK kinase is a substrate and target of PKCtheta in T-cell receptor-induced AP-1 activation pathway. EMBO J. 23, 1112-1122.

Liszewski, M. K., Leung, M., Cui, W., Subramanian, V. B., Parkinson, J., Barlow, P. N., Manchester, M., and Atkinson, J. P. (2000). Dissecting sites important for complement regulatory activity in membrane cofactor protein (MCP; CD46). J. Biol. Chem. 275, 37692-37701.

Liszewski, M. K., Post, T. W., and Atkinson, J. P. (1991). Membrane cofactor protein (MCP or CD46): newest member of the regulators of complement activation gene cluster. Annu. Rev. Immunol. 9, 431-455.

Lotz, M., Menard, S., and Hornef, M. (2007). Innate immune recognition on the intestinal mucosa. Int. J. Med. Microbiol. 297, 379-392.

Ludford-Menting, M. J., Thomas, S. J., Crimeen, B., Harris, L. J., Loveland, B. E., Bills, M., Ellis, S., and Russell, S. M. (2002). A functional interaction between CD46 and DLG4: a role for DLG4 in epithelial polarization. J. Biol. Chem. 277, 4477-4484.

Menard, S., Cerf-Bensussan, N., and Heyman, M. (2010). Multiple facets of intestinal permeability and epithelial handling of dietary antigens. Mucosal Immunol. 3, 247-259.

Moon, R., Parikh, A. A., Szabo, C., Fischer, J. E., Salzman, A. L., and Hasselgren, P. O. (1997). Complement C3 production in human intestinal epithelial cells is regulated by interleukin lbeta and tumor necrosis factor alpha. Arch. Surg. 132, 1289-1293.

Mueller, C., and Macpherson, A. J. (2006). Layers of mutualism with commensal bacteria protect us from intestinal inflammation. Gut 55, 276-284.

Nakamura, R., Watanabe, M., Sugimura, Y., Matsuno, S., Sato, T., Ishida, K., and Saito, K. (1995). Changes in wound healing factors in liver cirrhosis after esophageal transection for esophageal varices. Hepatogastroenterology 42, 43-46.

Ogura, Y., Bonen, D. K., Inohara, N., Nicolae, D. L., Chen, F. F., Ramos, R., Britton, H., Moran, T., Karaliuskas, R., Duerr, R. H., Achkar, J. P., Brant, S. R., Bayless, T. M., Kirschner, B. S., Hanauer, S. B., Nuñez, G., and Cho, J. H. (2001). A frameshift mutation in NOD2 associated with susceptibility to Crohn's disease. Nature 411, 603-606.

Peignon, G., Durand, A., Cacheux, W., Ayrault, O., Terris, B., Laurent-Puig, P., Shroyer, N. F., Van Seuningen, I., Honjo, T., Perret, C., and Romagnolo, B. (2011). Complex interplay between beta-catenin signalling and Notch effectors in intestinal tumorigenesis. Gut 60, 166-176.

Ricklin, D., Hajishengallis, G., Yang, K., and Lambris, J. D. (2010). Complement: a key system for immune surveillance and homeostasis. Nat. Immunol. 11, 785-797.

Riley, R. C., Tannenbaum, P. L., Abbott, D. H., and Atkinson, J. P. (2002). Cutting edge: inhibiting measles virus infection but promoting reproduction: an explanation for splicing and tissue-specific expression of CD46. J. Immunol. 169, 5405-5409.

Riley-Vargas, R. C., Gill, D. B., Kemper, C., Liszewski, M. K., and Atkinson, J. P. (2004). CD46: expanding beyond complement regulation. Trends Immunol. 25, 496-503.

Sanchez, A., Feito, M. J., and Rojo, J. M. (2004). CD46-mediated costimulation induces a Th1-biased response and enhances early TCR/CD3 signaling in human $\mathrm{CD}^{+} \mathrm{T}$ lymphocytes. Eur. J. Immunol. 34, 2439-2448.

San-Cristobal, P., Pacheco-Alvarez, D. Richardson, C., Ring, A. M., Vazquez, N., Rafiqi, F. H., Chari, D., Kahle, K. T., Leng, Q., Bobadilla, N. A., Hebert, S. C., Alessi, D. R., Lifton, R. P., and Gamba, G. (2009). Angiotensin II signaling increases activity of the renal $\mathrm{Na}-\mathrm{Cl}$ cotransporter through a WNK4-SPAK-dependent pathway. Proc. Natl. Acad. Sci. U.S.A. 106, 4384-4389.

Sansonetti, P. J. (2004). War and peace at mucosal surfaces. Nat. Rev Immunol. 4, 953-964.

Sinn, P. L., Williams, G., Vongpunsawad, S., Cattaneo, R., and McCray, P. B. Jr. (2002). Measles virus preferentially transduces the basolateral surface of well-differentiated human airway epithelia. J. Virol. 76, 2403-2409.

Sjoblom, T., Jones, S., Wood, L. D., Parsons, D. W., Lin, J., Barber, T. D. Mandelker, D., Leary, R. J., Ptak, J. Silliman, N., Szabo, S., Buckhaults, P., Farrell, C., Meeh, P., Markowitz, S. D., Willis, J., Dawson, D., Willson, J. K., Gazdar, A. F., Hartigan, J., Wu, L., Liu, C., Parmigiani, G., Park, B. H., Bachman, K. E., Papadopoulos, N., Vogelstein, B., Kinzler, K. W., and Velculescu, V. E. (2006). The consensus coding sequences of human breast and colorectal cancers. Science 314, 268-274.

Smith, L., Smallwood, N., Altman, A., and Liedtke, C. M. (2008). PKCdelta acts upstream of SPAK in the activation of NKCC1 by hyperosmotic stress in human airway epithelial cells. J. Biol. Chem. 283, 22147-22156.

Strauss, R., Sova, P., Liu, Y., Li, Z. Y. Tuve, S., Pritchard, D., Brinkkoetter, P., Moller, T., Wildner, O., Pesonen, S., Hemminki, A., Urban, N. Drescher, C., and Lieber, A. (2009). Epithelial phenotype confers resistance of ovarian cancer cells to oncolytic adenoviruses. Cancer Res. 69, 5115-5125.

Van Aken, E., De Wever, O., Correia da Rocha, A. S., and Mareel, M. (2001). Defective E-cadherin/catenin complexes in human cancer. Virchow Arch. 439, 725-751.
Vermeulen, S. J., Nollet, F., Teugels, E., Vennekens, K. M., Malfait, F., Philippe, J., Speleman, F., Bracke, M. E., van Roy, F. M., and Mareel, M. M. (1999). The alphaEcatenin gene (CTNNA1) acts as an invasion-suppressor gene in human colon cancer cells. Oncogene 18, 905-915.

Wang, G., Liszewski, M. K., Chan, A. C., and Atkinson, J. P. (2000) Membrane cofactor protein (MCP; CD46): isoform-specific tyrosine phosphorylation. J. Immunol. 164, 1839-1846.

Yamada, S., Pokutta, S., Drees, F., Weis, W. I., and Nelson, W. J. (2005) Deconstructing the cadherincatenin-actin complex. Cell 123, 889-901.

Yan, Y., Dalmasso, G., Nguyen, H. T., Obertone, T. S., Sitaraman, S. V., and Merlin, D. (2009). Ste20related proline/alanine-rich kinase (SPAK) regulated transcriptionally by hyperosmolarity is involved in intestinal barrier function. PLoS ONE 4, e5049. doi: 10.1371/journal.pone.0005049

Yan, Y., Nguyen, H., Dalmasso, G., Sitaraman, S. V., and Merlin, D. (2007). Cloning and characterization of a new intestinal inflammation-associated colonic epithelial Ste20-related protein kinase isoform. Biochim. Biophys. Acta 1769, 106-116.

Zeng, Q., and Hong, W. (2008). The emerging role of the hippo pathway in cell contact inhibition, organ size control, and cancer development in mammals. Cancer Cell 13, 188-192.

Conflict of Interest Statement: The authors declare that the research was conducted in the absence of any commercial or financial relationships that could be construed as a potential conflict of interest.

Received: 16 May 2011; accepted: 22 June 2011; published online: 07 July 2011.

Citation: Cardone J, Al-Shouli $S$ and Kemper C (2011) A novel role for CD46 in wound repair. Front. Immun. 2:28. doi: 10.3389/fimmu. 2011.00028

This article was submitted to Frontiers in Molecular Innate Immunity, a specialty of Frontiers in Immunology.

Copyright () 2011 Cardone, Al-Shouli and Kemper. This is an open-access article subject to a non-exclusive license between the authors and Frontiers Media $S A$, which permits use, distribution and reproduction in other forums, provided the original authors and source are credited and other Frontiers conditions are complied with. 